\title{
An experimental analysis of overconfidence in tariff choice
}

\author{
Katharina Dowling ${ }^{1} \cdot$ Lucas Stich $^{1} \cdot$ Martin Spann $^{1}[$
}

Received: 26 January 2020 / Accepted: 16 November 2020

(C) The Author(s) 2020

\begin{abstract}
Consumers regularly have to choose between a pay-per-use and a flat-rate option. Due to the increasing number and range of (digital) services, the frequency at which consumers have to make tariff-choice decisions to use these services has become even more prevalent. Prior work has demonstrated that consumers' tariff choices are often systematically biased and identified overconfidence as one of the key drivers. Yet, prior research is non-experimental and focused on the so-called flat-rate bias. By contrast, we examine the effects of overconfidence on the choice between a pay-per-use and a flat-rate option using an experimental approach. We develop an incentive-compatible experiment to provide causal evidence for the effect of overconfidence on tariff-choice decisions. We find that overconfident (underconfident) consumers underestimate (overestimate) their actual usage, which leads them to choose a pay-per-use (flat-rate) option relatively more frequently. Based on the results, we discuss theoretical and managerial implications as well as avenues for future research.
\end{abstract}

Keywords Overconfidence $\cdot$ Tariff choice $\cdot$ Pay-per-use $\cdot$ Flat-rate $\cdot$ Experiment

JEL Classification M31 · D91 · D12 · D84 · C90

Martin Spann

spann@spann.de

Katharina Dowling

katharina.dowling@gmail.com

Lucas Stich

stich@1mu.de

1 Ludwig-Maximilians-Universität München, Geschwister-Scholl-Platz 1, 80539 Munich, Germany 


\section{Introduction}

Consumers regularly face the decision between a pay-per-use and a flat-rate option. Owing to the increasing number and range of (digital) services, the frequency at which consumers have to make such tariff-choice decisions to use these services has also become more prevalent. For example, cloud services (e.g., computing power or storage) and various apps (e.g., for sports, media, meditation) involve the choice between a pay-per-use and a flat-rate subscription. Even ride sharing services like Uber or Lyft that started with pay-per-use pricing only, now offer monthly flat-rates for reduced-cost rides (Hempel 2018; Matousek 2018). Consequently, even small mistakes in individual tariff choices may add up to a substantial overall financial loss across all service categories. As choosing the wrong tariff can result in consumers' dissatisfaction and eventually churn (e.g., Lambrecht and Skiera 2006), better understanding consumers' (potentially non-optimal) tariff choices is important for both consumers and service providers.

Prior research has widely documented that consumers do not always make optimal (i.e., cost-minimizing) tariff-choice decisions (e.g., DellaVigna and Malmendier 2006; Lambrecht and Skiera 2006). Such non-optimal choices can be driven either (1) by behavioral biases ${ }^{1}$ or (2) by consumers having a tariff-specific preference for the more expensive tariff. With respect to (1), belief-based biases are a leading candidate in the context of tariff-choice decisions. Belief-based biases arise when uncertainty factors into decisions. Under uncertainty, decision-makers must form beliefs regarding potential outcomes or "states of the world" (DellaVigna 2009; Rabin 2002). In tariff-choice decisions, consumers are faced with demand uncertainty at the tariff-choice stage, because of a time lag between the tariff-choice decision and later usage decisions (Nunes 2000). For example, when consumers want to sign up for a gym membership, they have to choose the tariff first, but decide only later on the individual trips to the gym. Therefore, it is likely that belief-based biases influence consumers' usage estimations and further their tariff-choice decisions. In particular, prior research proposed overconfidence as one of the main drivers of tariff choice (e.g., DellaVigna and Malmendier 2006; Grubb 2009). These studies typically infer overconfidence from comparing contract choices to later usage by analyzing observational or survey data. Yet, causal evidence is lacking.

The goal of this paper is to examine the effect of overconfidence on tariff-choice decisions. To this end, we develop an incentive-compatible online experiment. The participants are randomly assigned to one of two treatments. We follow established procedures in the literature (Dargnies et al. 2019) to first induce overconfidence (over treatment) or underconfidence (under treatment) in our participants. Using a memory game, we then model the essential parts of real-world tariff choices, including the prediction of usage, the choice of a tariff, and finally the usage/consumption of the product, to examine the effects of overconfidence/underconfidence on participants' choice between a pay-per-use and a flat-rate option.

\footnotetext{
1 For a review of behavioral biases in marketing see Dowling et al. (2020).
} 
Our contribution is a novel, incentive-compatible experimental paradigm and the causal evidence that our experimental approach provides. We show that overconfidence (underconfidence) leads to an underestimation (overestimation) of actual usage, and thereby to a relatively higher pay-per-use (flat-rate) choice. This causal evidence is crucial for the theoretical and managerial implications as well as avenues for future research that we discuss based on our findings.

\section{Literature review}

One can distinguish two broad streams of literature in tariff research. One stream of literature analyzes drivers of tariff choice (e.g., DellaVigna and Malmendier 2006; Uhrich et al. 2013). The other stream of literature studies consumer behavior given a chosen tariff (e.g., Iyengar et al. 2011; Leider and Şahin 2014). Focusing on tariff choice, several studies showed that consumers do not always select the tariff that minimizes their billing rate (e.g., DellaVigna and Malmendier 2006; Lambrecht and Skiera 2006; Train et al. 1987; Uhrich et al. 2013). The majority of these studies finds mostly flat-rate choices and documents a flat-rate bias ${ }^{2}$ (DellaVigna and Malmendier 2006; Lambrecht and Skiera 2006; Uhrich et al. 2013; Herweg and Mierendorff 2013). DellaVigna and Malmendier (2006), for example, found that consumers chose the flat-rate tariff too often in a gym setting, and Lambrecht and Skiera (2006) showed that consumers primarily had a flat-rate bias in the context of internet access. A few studies also analyzed the pay-per-use choice and pay-per-use bias (e.g., Lambrecht and Skiera 2006; Miravete 2002). For instance, Lambrecht and Skiera (2006) demonstrate that the pay-per-use bias (in contrast to the flat-rate bias) only occurs irregularly and that it seems to lead to higher churn. For both tariffs, most studies identify drivers of tariff choice based on findings from observational or survey data.

Two explanations for non-optimal tariff-choice decisions have been proposed. First, consumers are inherently prone to biases (nonstandard preferences, nonstandard beliefs, and nonstandard decision-making; see DellaVigna 2009), leading them to commit errors. Regarding nonstandard preferences, DellaVigna and Malmendier (2006), for example, suggest that time-inconsistent preferences can induce a flat-rate bias. Concerning nonstandard beliefs, consumers are likely to form incorrect beliefs about their future usage (Nunes 2000), resulting in misforecasting and non-optimal tariff-choice decisions or the overestimation of their abilities to navigate contract terms (Grubb 2015b). Finally, framing effects (as an example of nonstandard decision-making) may systematically influence consumers' tariff choices. Equivalent but

\footnotetext{
${ }^{2}$ Note that both flat-rate "bias" and pay-per-use "bias" do not refer to behavioral biases in the sense of deviations from the standard economic model, but rather deviations from the optimal (i.e., cost-minimizing) tariff choice.
} 
differently framed decision problems may cause individuals to shift or reverse their preferences and elicit different behavioral reactions.

The second explanation is that consumers have a preference ${ }^{3}$ for a respective tariff and deliberately choose the more expensive tariff. Lambrecht and Skiera (2006) analyze causes of such tariff-specific preferences. They demonstrate that the so-called insurance effect (i.e., aversion to variations in monthly bill amounts) and taxi-meter effect (i.e., when the ticking taxi meter lowers the consumption enjoyment) lead to a flat-rate bias. Uhrich et al. (2013) replicate these findings and show that consumers with a more hedonic consumption goal exhibit a stronger preference for the flatrate, whereas consumers with a more utilitarian consumption goal exhibit a stronger preference for the pay-per-use plan. Their study also implies that the context (i.e., hedonic vs. utilitarian setting) influences whether a greater choice of the flat-rate or the pay-per-use plan can be expected.

Both explanations can drive tariff-choice decisions, they are, however, not mutually exclusive, but may also interact. Assume, for example, a consumer prefers a flat-rate over a pay-per-use tariff due to the taxi-meter effect. Given this preference, consumers may form biased beliefs about their estimated usage (i.e., too high) to justify their preference and resulting choice to avoid cognitive dissonance.

This paper is primarily concerned with the first explanation for non-optimal tariff-choice decisions, in particular with belief-based biases. Belief-based biases emerge in the presence of uncertain factors in decision-making. Under uncertainty, decision-makers must form beliefs regarding potential outcomes or "states of the world". To illustrate this more formally, consider the following version of the standard economic model, formulated by Rabin (2002) and then modified by DellaVigna (2009):

$$
\max _{x_{i}^{t} \in X_{i}} \sum_{t=0}^{\infty} \delta^{t} \sum_{s_{t} \in S_{t}} p\left(s_{t}\right) U\left(x_{i}^{t} \mid s_{t}\right)
$$

In this formulation, individual $i$ maximizes expected utility at time $t=0$, subject to a probability distribution $p\left(s_{t}\right)$ of the "states of the world" $s_{t} \in S_{t} . U\left(x_{i}^{t} \mid s_{t}\right)$ is the utility function, defined over individual $i$ 's payoff $x_{i}^{t}$. The time-consistent discount factor of future utility is denoted by $\delta$. Nonstandard beliefs refer to ways people are having systematically distorted beliefs $\tilde{p}\left(s_{t}\right)$ about the distribution of the "states of the world" $p\left(s_{t}\right)$, such that $\tilde{p}\left(s_{t}\right) \neq p\left(s_{t}\right)$. One way in which individuals have been found to form such systematically incorrect beliefs is the overprojection of their current preferences (e.g., taste or hunger) on future preferences (Loewenstein et al. 2003). Another form of incorrect beliefs is overconfidence, for example about ability [e.g., to solve a puzzle (Camerer and Lovallo 1999) or to manage a company (Malmendier and Tate 2015)].

\footnotetext{
3 Note that we use the term tariff-specific preference in the sense of "liking" or "preferring" a specific tariff over another. Here, we do not refer to preferences as defined in the standard economic model or deviations thereof (i.e., nonstandard preferences).
} 


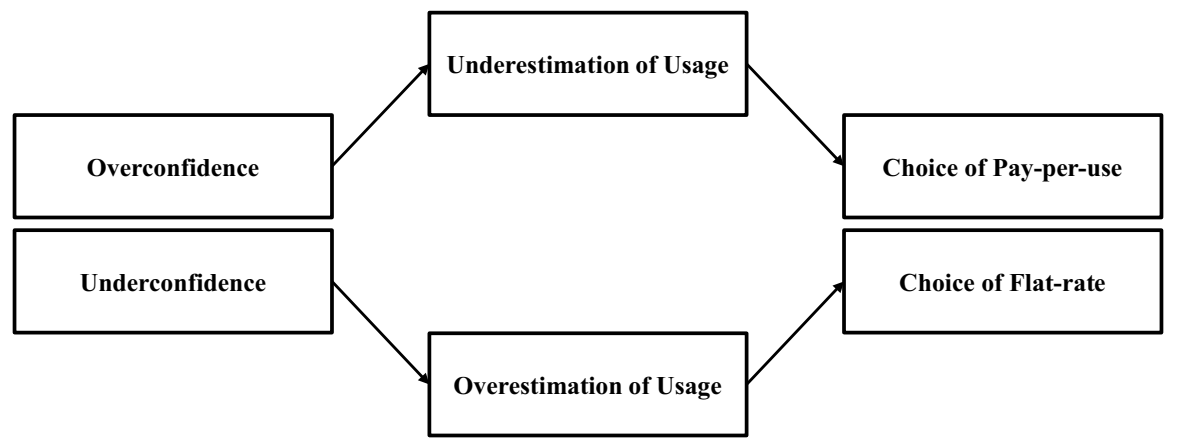

Fig. 1 Predictions

Regarding possible belief-based biases influencing tariff choice, previous research proposed overconfidence as a key driver (e.g., DellaVigna and Malmendier 2006; Grubb and Osborne 2015; Grubb 2015a). The empirical literature defines overconfidence in three distinct ways (Moore and Healy 2008). The first facet of overconfidence is overestimation, which is defined by overestimating one's actual ability, performance, level of control, or chance of success. The second facet of overconfidence is overprecision, which is the excessive certainty regarding the accuracy of one's beliefs. The third facet of overconfidence is overplacement, which occurs when people consider their abilities to be better than average.

DellaVigna and Malmendier (2006), for example, propose that overconfidence about future self-control is a main driver of the substantial flat-rate bias they observe. Grubb and Osborne (2015) argue that consumers are overconfident in the sense that they underestimate the variance of their future consumption and thereby choose overly risky plans (in the context of a cellular service). Grubb (2015a) further suggests that naive inattention may explain the presence of overconfidence that Grubb and Osborne (2015) estimate. He shows that overconfidence leads naively inattentive customers to underestimate the probability of paying surprise penalty fees.

Importantly, whether overconfidence leads to overestimation or underestimation (of usage) seems to depend on the underlying setting. Overestimation appears to occur when a higher usage is desirable (e.g., gym setting), whereas underestimation appears to occur when a lower usage/cost is desirable (e.g., cellular service). Overall, overconfidence has been proposed as a key driver of tariff choice across multiple industries (e.g., gym memberships, internet access, or optional calling plans) and methods (observational data: e.g., DellaVigna and Malmendier 2006 or analytical modeling: e.g., Grubb 2015a). However, to the best of our knowledge, no study has yet experimentally studied the effect of overconfidence on tariff choice. Yet, identifying causal relationships is crucial for deriving effective managerial implications. Managers aiming to reduce potential adverse effects of overconfidence should only invest in such measures if a causal relationship exists to avoid ineffective investments. For example, Grubb and Osborne (2015) analyze the effectiveness of alerts that customers receive when they exceed their allowance. They show that alerts are 
only effective if consumers are overconfident. Otherwise, alerts would have no effect and managers would have wasted resources.

In this research, we propose that overconfident consumers underestimate their actual usage, similar to the argument by Grubb and Osborne (2015), who suggest that overconfident consumers underestimate the variance of their future consumption. Next, having underestimated their usage, we predict that overconfident consumers are more likely to choose a pay-per-use (vs. a flat-rate) option. We expect the opposite effect for underconfident consumers. We illustrate our prediction in Fig. 1.

\section{Method}

\subsection{Participants}

We recruited $411^{4}$ US-based participants $\left(48.91 \%\right.$ female, $\mathrm{M}_{\mathrm{age}}=38.07$ years, $\mathrm{SD}=11.31$ years) from an online crowdsourcing platform for human intelligence tasks (HITs)-Amazon Mechanical Turk (MTurk). Participants completed the experiment through the web-based survey software Qualtrics in exchange for a fixed fee and an additional bonus payment that depended on participants' behavior in the experiment. ${ }^{5}$ On average, participants completed the experiment in about $10 \mathrm{~min} .{ }^{6}$

\subsection{Design and procedure}

The study consisted of three parts (see Fig. 2): the treatment phase (manipulation of overconfidence), a second part including estimation of usage, tariff choice, and completion of a usage task, and a third part consisting of process and belief measures.

We conducted an incentive-compatible experiment using a between-subjects design. In the treatment phase, we randomly assigned participants to one of two treatments: underconfidence and overconfidence. To manipulate overconfidence, we built on the "hard-easy effect" (Lichtenstein et al. 1982). More specifically, we followed the approach of Dargnies et al. (2019). They used two different tasks to exogenously manipulate the self-confidence of their study participants. In that study,

\footnotetext{
${ }^{4}$ We used comprehension questions to screen participants for participation in the key experimental task. Of the 443 participants that accessed our study through Amazon Mechanical Turk (MTurk), only 32 (7\%) repeatedly failed to answer the comprehension questions correctly and therefore were not admitted to the main study. The 32 respondents excluded from participation split up almost equally between the two treatments (15 in the under treatment, 17 in the over treatment). Only 5.7\% $(27 /(443+27))$ of participants started but did not finish the experiment (most not proceeding beyond the starting page). There is a slight difference in dropouts between treatments (20 in the under treatment, 7 in the over treatment). The following results are based on the 411 participants who passed the comprehension questions and finished the experiment.

5 The fixed fee was $\$ 1.00$. Participants that chose the pay-per-use option received an average bonus payment of $\$ 0.93$, with a minimum of $\$ 0$ and a maximum of $\$ 1.40$.

${ }^{6}$ In a pilot study, we observed that participants in the under treatment needed more time to answer the questions than the participants in the over treatment. Therefore, we increased the number of questions in the over treatment to achieve approximately the same average duration of the treatment phase.
} 


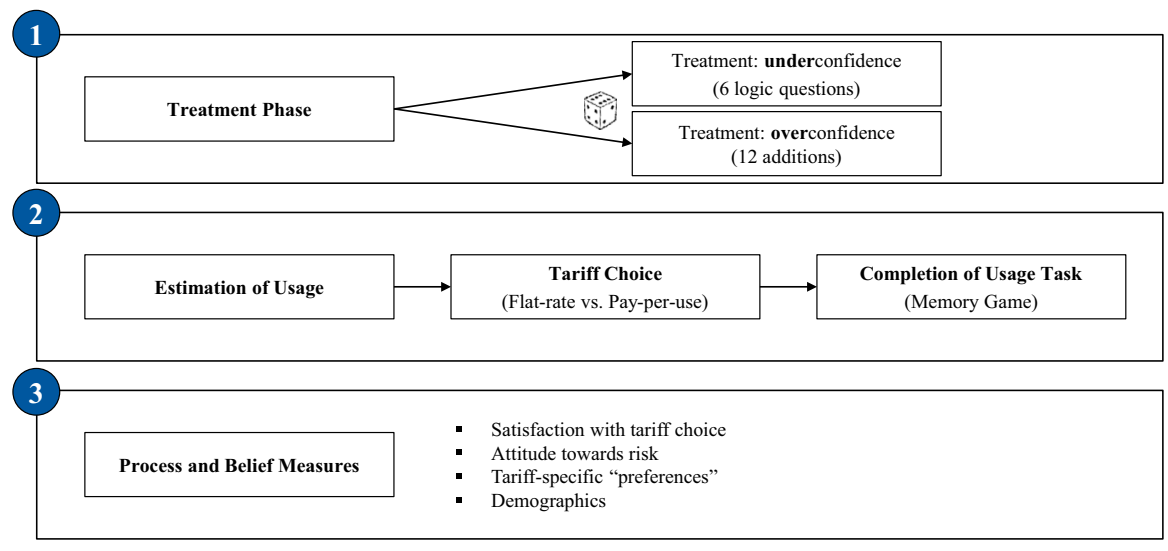

Fig. 2 Overview of the three parts of the study

the goal was to shift participants' beliefs about their performance and then to test how this shift influences market outcomes.

In our treatments, participants had to complete a real-effort task. In the under treatment, participants had to solve 6 logic questions taken from IQ tests (see "Appendix", Table 3). This task was difficult for participants as there was no clear technique that could be applied to answer the questions and we expected them to answer only a small number of the questions correctly (Dargnies et al. 2019). In the overconfidence treatment, participants had to solve 12 easy additions (see "Appendix", Table 3). This task was easy for participants because they were familiar with the task and we expected them to answer a large number of the questions correctly (Niederle and Vesterlund 2007; Dargnies et al. 2019). ${ }^{7}$ We presented the questions sequentially. Participants received feedback on whether they had answered a question correctly or not after each question. The aim of this manipulation was to induce relative underconfidence in the under treatment with the difficult task and relative overconfidence in the over treatment with the easy task (Dargnies et al. 2019; Cain et al. 2015; Niederle and Vesterlund 2007). After they completed the real-effort tasks, we asked participants to state what percentage of other participants they thought answered more questions correctly than they did (i.e., a better-than-average measure; Alicke and Govorun 2005).

In the second part of the study, we asked participants to estimate their usage in a usage task, to choose between a flat-rate and a pay-per-use option for this task, and then to complete the task (see Fig. 2). These three steps were designed to reflect the real-world situation of tariff-choice decisions including the prediction of usage, the choice of the corresponding tariff, and finally using/consuming the product. We

\footnotetext{
7 Participants could have used calculators to solve the addition tasks in the over treatment. However, using a calculator is not a problem, as this would have made the task even easier and possibly increased the induced overconfidence, in contrast to the under treatment, in which no tool would have made the task easier.
} 
operationalized the usage task as a memory game due to its resemblance to tariffchoice decisions.

The memory game as our usage task enabled us to mirror the sequence of steps in tariff-choice decisions: estimation—choice—task completion. Moreover, our memory game had the advantage that participants most likely already had some experience with the game. Therefore, they could approximate how many clicks they might need, yet a moderate level of uncertainty about their estimated usage remained-as one would expect in a real-world tariff-choice situation. Another advantage of the memory game is that it is applicable to computation scenarios that require judgment. Therefore, the memory game is well suited for service contexts in which consumers have to make judgments about consumption and cost. In this regard, the task is similar to other judgment tasks such as the "dot-guessing game" (Horton 2010) and the "ball-catching task" (Gächter et al. 2016). Finally, the memory game requires participants to use their cognitive abilities, which has been shown to be an important aspect in situations involving usage estimation (see e.g., Nunes 2000).

Our usage task aimed to mimic a rather utilitarian (vs. hedonic) tariff-choice situation. Whereas in a hedonic context consumers should typically strive for maximizing their usage (e.g., gym setting), we should expect consumers in a utilitarian context to try to minimize their usage and corresponding cost (e.g., public transportation). Because each unit of "usage" in the memory game is costly under the payper-use option, we expected participants to strive to minimize "usage" and thereby total cost.

We showed participants the memory game consisting of 16 tiles with food icons, as depicted in Fig. 5 in the "Appendix". Moreover, we told them that participants needed on average 32 clicks to solve the memory game, which we learned in a pilot study $(\mathrm{N}=45)$. Thereafter, we asked participants to state their estimate of how many clicks they thought they would need to solve the memory game and to state their confidence with regard to this estimate. ${ }^{8}$ Next, participants were presented with the choice between a flat-rate option and a pay-per-use option (called pay-per-click option in the experiment). To make the choice consequential for participants, they received a bonus payment depending on their chosen option. Under the flat-rate option, participants received a fixed bonus of $\$ 0.80$, regardless of the number of clicks they needed to solve the memory game. Under the pay-per-use option, participants received a bonus between $\$ 0$ and $\$ 1.60$, depending on the number of clicks they needed to solve the memory game (a cost per click of $\$ 0.05$ was subtracted from \$2.40; see Fig. 6 in the “Appendix"). We used the average of 32 clicks from the pilot study to parameterize the two tariff options such that the expected value of the bonus was the same for the two options $(\$ 0.80)$. Next, participants proceeded to the actual tariff choice and then completed the memory game. Upon completion of the

\footnotetext{
8 We explicitly told participants what the task entailed and illustrated this with a graphical depiction. In addition, we told participants explicitly and truthfully how many clicks participants needed on average to complete the task (from the pilot study). It is therefore unlikely that participants had biased beliefs about the difficulty of the memory task.
} 
memory game, we told participants how many clicks they actually needed to solve it and what their bonus payment and total payout was.

In the last part of the study, we asked participants to answer process and belief measures. These measures included questions and scales regarding satisfaction with their chosen tariff, attitude towards risk, tariff-specific preferences, and demographics.

\subsection{Measures}

This section summarizes all measures we elicited throughout the study. After the manipulation of overconfidence, we asked participants to answer two manipulation checks. We asked them to rate the perceived task difficulty (7-point scale; $1=$ "not difficult at all" $-7=$ "very difficult") and to indicate the percentage of other participants that they believed had answered more questions correctly then they had (i.e., the better-than-average measure; $0-100 \%{ }^{9}$; Alicke and Govorun 2005). After illustrating and explaining the memory game, we asked participants to estimate the number of clicks they would need to solve the memory game and to rate their confidence with regard to this estimation (7-point scale; $1=$ "not confident at all" $-7=$ "very confident"). Apart from the absolute number of estimated clicks, we also calculated an overestimation measure (= estimated clicks - actual clicks; Cain et al. 2015). Next, participants made their choice between the two tariff options $(0=$ pay-peruse; $1=$ flat-rate). After their choice, we asked participants to rate their satisfaction with the chosen tariff (7-point scale; $1=$ "not satisfied at all" $-7=$ "very satisfied"; Novemsky and Schweitzer 2004). In the last part of the study, we asked participants to rate their willingness to take risks (7-point scale; $1=$ "completely unwilling to take risks" $-7=$ "completely willing to take risks"; Dohmen et al. 2011), to complete Lambrecht and Skiera's (2006) scales regarding tariff-specific preferences - insurance, taxi meter, and convenience effects - (for all constructs: 7-point scale; 1 = "strongly disagree" $-7=$ "strongly agree"), and to provide demographic information: age, sex $(0=$ female; $1=$ male $)$, income, and employment status. We provide a detailed overview of all measures in Table 4 in the "Appendix".

\section{Results}

Manipulation checks We conducted Mann-Whitney-U tests for task difficulty and the better-than-average measure, as these variables were not normally distributed. In terms of task difficulty, the results confirmed that participants in the under treatment perceived their questions to be more difficult than the participants in the over treatment $\left(\mathrm{M}_{\text {under }}=6.46, \mathrm{M}_{\text {over }}=1.45, \mathrm{z}_{\text {Mann-Whitney-U }}=17.94, p<.001\right)$. Comparing the better-than-average measure between treatments showed that participants in the under treatment were more underconfident and participants in the over treatment

\footnotetext{
${ }^{9}$ We calculate the better-than-average measure as (50 - answer)/50, following Glaser and Weber (2007).
} 
Table 1 Estimated and actual number of clicks

\begin{tabular}{lllll}
\hline Treatment & $\mathrm{N}$ & $\begin{array}{l}\text { Estimated clicks } \\
(\text { mean })(1)\end{array}$ & $\begin{array}{l}\text { Actual clicks } \\
(\text { mean })(2)\end{array}$ & $\begin{array}{l}\text { Overestimation measure (3) } \\
=(1)-(2)\end{array}$ \\
\hline Under & 201 & 33.65 & 30.99 & 2.66 \\
Over & 210 & 30.91 & 32.16 & -1.25 \\
\hline
\end{tabular}

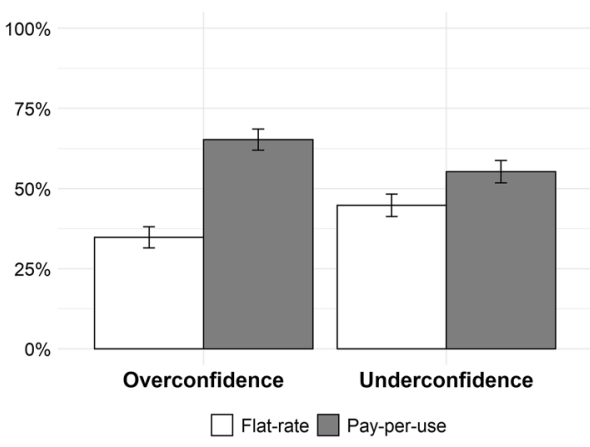

Fig. 3 Choice of flat-rate and pay-per-use option by treatment

more overconfident $\left(\mathrm{M}_{\text {under }}=-.22, \mathrm{M}_{\text {over }}=.39, \mathrm{z}_{\text {Mann-Whitney-U}}=-8.07, p<.001\right)$. Regarding task performance, as expected, the majority of participants in the under treatment only answered very few questions correctly (mostly 0-1 out of 6). Yet, participants in the over treatment answered the majority of questions correctly (mostly 11-12 out of 12).

Estimated and actual number of clicks We found that overconfident participants underestimated their actual usage, whereas underconfident consumers overestimated their actual usage (see Table 1). Mann-Whitney-U tests showed that the estimated number of clicks was significantly different between treatments $\left(\mathrm{M}_{\text {under }}=33.65, \mathrm{M}_{\text {over }}=30.91, \mathrm{z}_{\text {Mann-Whitney-U }}=3.44, p<.001\right)$. We found no statistically significant difference in the actual number of clicks, but the overestimation measure was again significantly different between treatments $\left(\mathrm{M}_{\text {under }}=2.66\right.$, $\left.\mathrm{M}_{\text {over }}=-1.25, \mathrm{z}_{\text {Mann-Whitney-U }}=2.80, p<.005\right)$.

Choice Overall, $39.66 \%$ of participants chose the flat-rate option and $60.34 \%$ chose the pay-per-use option. In absolute terms, the majority of participants chose the pay-per-use option in both treatment groups, as evidenced by Fig. 3. However, there are significant relative differences between treatments. We found that participants in the over treatment chose the pay-per-use (vs. the flat-rate) option relatively more often than participants in the under treatment $\left(\mathrm{M}_{\text {under }}=.55, \mathrm{M}_{\text {over }}=.65\right.$, $\mathrm{Z}_{\text {Mann-Whitney-U }}=-2.07, p=.038$ ). Participants in the under treatment in turn chose the flat-rate (vs. the pay-per-use) option relatively more often than participants in the over treatment. 
In addition, we analyzed the consistency of participants' tariff choices. We compared whether the chosen tariff was coherent with their stated estimates of clicks. More specifically, if participants estimated that they needed less than 32 clicks, they should have taken the pay-per-use option to maximize their payout, yet if they had estimated that they needed more than 32 clicks, they should have taken the flat-rate option. However, we found that $27 \%$ of participants did not choose the tariff option that would have matched their estimate. Broken down by treatment, $22 \%$ of participants in the under treatment and $31 \%$ of participants in the over treatment chose a tariff that did not match their optimal choice given their stated estimated clicks. We did not observe any systematic differences in terms of the chosen tariff, as the nonconsistent choices comprised $52 \%$ pay-per-use and $48 \%$ flat-rate.

In line with previous research, this result suggests that at least some of these participants had a preference for a specific tariff and therefore deliberately chose the more expensive tariff. ${ }^{10}$ Consistent with this argument, results of a Mann-Whitney-U test indeed showed that participants with non-consistent choices scored higher on the scales for tariff-specific preferences than participants with a consistent choice (using an index of tariff-specific preferences ${ }^{11}: \mathbf{M}_{\text {consistent }}=13.19$, $\left.\mathrm{M}_{\text {not consistent }}=14.16, \mathrm{z}_{\text {Mann-Whitney-U }}=2.34, p=.019\right)$.

Regression To control for additional drivers of tariff choice, we ran a logistic regression model with overconfidence $(0=$ underconfidence; $1=$ overconfidence $)$, attitude towards risk (7-point scale; 1 = "completely unwilling to take risks" $-7=$ "completely willing to take risks"), an index of tariff-specific preferences, age, sex ( $0=$ female; $1=$ male), and income (categorical, "up to $\$ 1000 "$ as baseline category) as the independent variables, and choice ( $0=$ pay-per-use; $1=$ flat-rate $)$ as the dependent variable.

As Table 2 shows, the results corroborate that overconfidence has a significant effect on tariff choice, even when controlling for tariff-specific preferences and demographics (model 1). Thus, overconfident participants were more likely to choose the pay-per-use option. Moreover, we replicate previous research by demonstrating that the higher the index for tariff-specific preferences, the more likely participants were to choose the flat-rate option. These results also hold when including a measure of risk preferences, although the effect of overconfidence is then only marginally significant ( $p=.055$, model 2 ). In line with previous research, risk-seeking participants were also more likely to choose the pay-per-use option and riskaverse participants were more likely to choose the flat-rate option (Lambrecht and Skiera 2006; Grubb 2009).

\footnotetext{
10 Although we provide some evidence that these participants were having a preference for the more expensive tariff, we cannot entirely rule out the possibility that they simply did not understand the rules of the game. However, since participants qualified to participate in the study by correctly answering comprehension questions, we are confident that this was not the case.

11 Since the tariff-specific preferences (insurance effect, taximeter effect, and convenience effect) according to Lambrecht and Skiera (2006) were highly correlated, we included an index of the three effects in the regressions, calculated as the sum of the scores of the three effects. Cronbach's $\alpha$ of the individual scales are: insurance effect $(\alpha=0.84)$, taximeter effect $(\alpha=0.86)$, and convenience effect $(\alpha=0.81)$.
} 
Table 2 Logistic regression analysis

\begin{tabular}{|c|c|c|c|c|}
\hline Tariff choice: & \multicolumn{2}{|l|}{ Model 1} & \multicolumn{2}{|l|}{ Model 2} \\
\hline \multicolumn{5}{|l|}{$1=$ flat-rate } \\
\hline $\begin{array}{l}\text { Treatment dummy }(0=\text { under } \\
1=\text { over })\end{array}$ & $-0.477 * *$ & $(0.214)$ & $-0.432 *$ & $(0.221)$ \\
\hline Attitude towards risk & & & $-0.315 * * *$ & $(0.069)$ \\
\hline Tariff preferences index & $0.171 * * *$ & $(0.033)$ & $0.185 * * *$ & $(0.034)$ \\
\hline Age & $-0.3 \times 10^{-3}$ & $(0.010)$ & $-0.4 \times 10^{-2}$ & $(0.010)$ \\
\hline Sex & 0.191 & $(0.216)$ & $0.397 *$ & $(0.227)$ \\
\hline \multicolumn{5}{|l|}{ Income $^{\mathrm{a}}$} \\
\hline$\$ 1001-\$ 2000$ & -0.569 & $(0.408)$ & -0.595 & $(0.419)$ \\
\hline$\$ 2001-\$ 3000$ & 0.158 & $(0.384)$ & 0.208 & $(0.390)$ \\
\hline$\$ 3001$ or above & 0.205 & $(0.358)$ & 0.259 & $(0.362)$ \\
\hline Constant & $-2.643 * * *$ & $(0.663)$ & $-1.560 * * *$ & $(0.708)$ \\
\hline Observations & 411 & & 411 & \\
\hline
\end{tabular}

Standard errors in parentheses

$* * * p<.01, * * p<.05, * p<0.1$

abaseline category: "up to $\$ 1000$ "

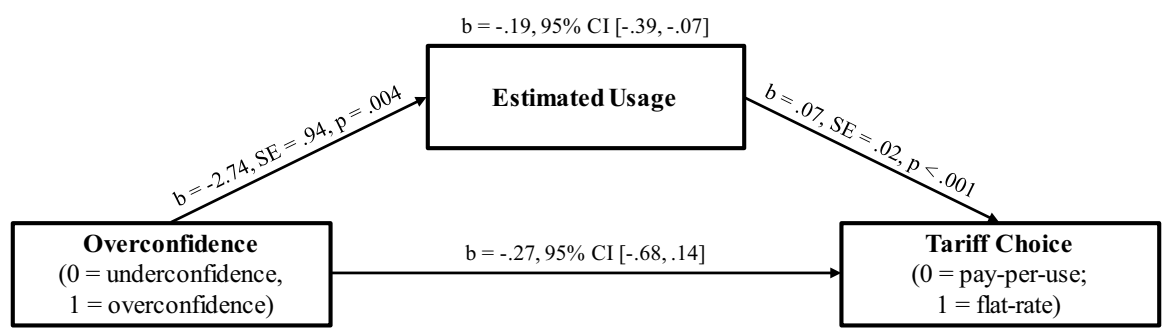

Fig. 4 Mediation analysis

Mediation analysis We conducted a mediation analysis (Hayes 2013; Model 4) to provide further evidence for our proposed psychological process. We used overconfidence (i.e., the treatment) as the independent variable $(0=$ underconfidence; $1=$ overconfidence), estimated usage as the mediator, and tariff choice as the dependent variable $(0=$ pay-per-use; $1=$ flat-rate $)$. As Fig. 4 shows, the results support the hypothesized model: overconfidence had a significant negative effect on estimated usage $(b=-2.74 ; \mathrm{SE}=.94 ; p=.004)$. Estimated usage had in turn a significant positive effect on tariff choice $(b=.07 ; \mathrm{SE}=.02 ; p<.001)$. Importantly, in support of our prediction, the overall indirect effect was significant, thus estimated usage significantly mediated the effect of overconfidence on tariff choice $(b=-.19$; 95\% CI [-.39, - .07]). Thus, overconfident participants underestimated their usage and were relatively more likely to choose the pay-per-use option. The opposite effect 
holds for underconfident participants. The direct effect of overconfidence on tariff choice was not significant $(b=-.27 ; 95 \%$ CI $[-.68, .14])$.

\section{Discussion and conclusion}

This paper examines the effects of overconfidence on tariff choice using an experimental approach. The results suggest that overconfidence leads to an underestimation of usage and as a result to a relative increase in the choice of a pay-per-use (vs. flat-rate) option. We observe the opposite effect for underconfident participants. These findings support many studies in both marketing and economics that proposed overconfidence as a key driver of tariff choice (e.g., DellaVigna and Malmendier 2006; Grubb 2009, 2015a; Lambrecht and Skiera 2006). We extend this prior research by establishing a causal relationship between overconfidence and tariff choice, and by proposing and analyzing a psychological process behind this relationship.

\subsection{Theoretical implications}

The central goal of many studies in various disciplines is to elucidate cause-effect relationships between variables. Prior research has successfully established an association (or correlation) between overconfidence and tariff-choice decisions from observational or survey data, but this is only a necessary not a sufficient condition for causal conclusions. For example, this identified relationship does not ensure that the variation in the independent variable came before the variation in the dependent variable nor does it rule out the possibility that the relationship is in fact spurious. Knowing what causes what is of crucial interest for researchers and managers alike. One of the most valuable methods to show causal relationships are experiments. To establish causal relationships it is crucial to have exogenous variation in variables that would otherwise be endogenous or confounded because of behavior, omitted variables, or selection effects (Reiss 2011). We provide such causal evidence for the relationship between overconfidence and tariff-choice decisions. Thereby, we augment prior research that has documented correlational relationships.

In the present research, we developed an incentive-compatible experiment in which participants were randomly assigned to one of two treatments inducing underconfidence and overconfidence respectively. Whereas multiple prior studies model overconfidence (e.g., Grubb 2009, 2015a) or rely on measurements of overconfidence (e.g., Glaser and Weber 2007; Ren and Croson 2013), we successfully manipulate participants' overconfidence. Moreover, the experimental economics literature suggests that salient, incentive-aligned monetary consequences will result in stronger out-of-sample predictive performance of actual behaviors and provide better estimates of consumer preference structures than hypothetical studies (e.g., Ding et al. 2005). By introducing our novel experimental paradigm, other researchers interested in tariff choice and overconfidence can now build on it. 


\subsection{Managerial implications}

Understanding drivers of tariff choice is essential for firms, as tariff choice and tariff characteristics can determine the satisfaction and thereby retention of customers (Becker et al. 2015). If customers are not satisfied with service quality, they are more likely to churn, which can be costly and threatening to the viability of business models and thus the survival of firms. Accordingly, our data also shows that participants who did not choose the optimal tariff (i.e., committed a flat-rate or payper-use error) were less satisfied with their choice $\left(\mathrm{M}_{\text {no error }}=6.31, \mathrm{M}_{\text {error }}=4.93\right.$, $\left.\mathrm{z}_{\text {Mann-Whitney-U }}=6.80, p<.001\right)$. However, we also look at the extent to which incorrectly choosing the pay-per-use option and incorrectly choosing the flat-rate option affects satisfaction. Interestingly, participants who committed a flat-rate error are more satisfied with their "error" than participants who committed a pay-per-use error $\left(\mathrm{M}_{\text {flat-rate error }}=5.49, \mathrm{M}_{\text {pay-per-use error }}=4.16, \mathrm{z}_{\text {Mann-Whitney-U }}=-2.90, p<.01\right)$. In summary, participants who made the correct tariff choice are more satisfied than participants who did not choose the optimal tariff. Among the participants who committed a tariff-choice error, however, those who made a flat-rate error are more satisfied with their choice than those who made a pay-per-use error.

When analyzing their customers' alleged tariff-choice errors, it is important for managers to identify its causes-tariff-specific preferences and/or behavioral biases. Depending on the cause, different managerial actions seem appropriate. Customers need not be dissatisfied with tariff-choice errors, if they have tariff-specific preferences. In these cases, managers can focus on measures like tariff structure optimization or cross-selling and upselling. By contrast, if tariff-choice errors are caused by biased beliefs, customers may be dissatisfied and eventually churn. Firms can address their customers' biased beliefs in two ways.

First, firms may exploit tariff-choice errors caused by behavioral biases of their customers for profit-maximizing purposes. For example, firms could design and communicate their tariffs and pricing in such a way that customers systematically choose a more expensive tariff than necessary. This may entail highlighting the unlimited usage of an expensive flat-rate tariff to exploit consumers' exaggerated usage estimations or increasing product uncertainty with the use of flexible products (e.g., Mang et al. 2012). Furthermore, firms could decide to only selectively inform their customers who make tariff-choice errors. For example, based on our results, firms could decide to inform only those customers that they would be better off in another tariff who are least satisfied with their tariff choice, in our case those who have made a pay-per-use error.

Second, managers may want to target customers with debiasing measures to improve satisfaction, which we outline next. With respect to tariff-choice errors due to overconfidence, firms could try to reduce the overconfidence of their customers by offering them decision aids to better estimate their usage, or by proactively offering them the cost-minimizing tariff to invest in their satisfaction and thus in a longterm relationship. One example of a firm that informs its customers about potentially avoidable costs is the streaming provider Netflix, which has recently started to cancel subscriptions of inactive customers. ${ }^{12}$

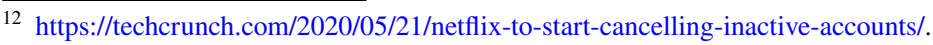


In a similar way, service providers could disclose more information on average monthly bills across all existing customers or make information about a customer's own past usage levels more salient to reduce misforecasting and potentially overconfidence. A potential motivation for such practices on the part of firms is that it can lead to greater customer loyalty and associated behavior (e.g., longer contract durations, cross-selling and upselling, positive word of mouth). But policy makers could even impose such measures on firms.

Our experimental approach to study the effect of overconfidence on tariff choice also has important implications for managers in terms of effective budget allocation. For example, developing and implementing decision aids for consumers as described above is a costly endeavor for a firm. Yet, in the absence of causal evidence, a firm cannot be sufficiently certain that such decision aids and the corresponding investments will be effective and thus justified. As outlined before, Grubb and Osborne (2015) examine the effectiveness of alerts that customers receive when they surpass their allowance. The authors demonstrate that such alerts are only effective if consumers are in fact overconfident. In the absence of overconfidence, sending out alerts would have no effect and managers would have spent scarce resources on ineffective interventions.

Our results are particularly informative for managers in service contexts that have utilitarian characteristics and in which usage estimations are common. In these settings, overconfidence is likely to influence tariff-choice decisions. Examples include subscription services in the domain of consumer products (e.g., razor blades, black socks, etc.), mobility services (e.g., car sharing, ride sharing), and novel utility services (e.g., electric vehicle charging).

Finally, while our study focuses on tariff-choice situations, the experimental design and results can also be extended to an employment context. Especially with the increasing presence and importance of so-called "gig economy" jobs, people can now more often and more flexibly choose between a "pay-per-use" (e.g., a gig economy job on Upwork) and a "flat-rate" job (i.e., fixed contract). Thereby, this paper also relates to studies analyzing the influence of biased beliefs on (employment) contract choices (e.g., Hoffman and Burks 2020; Spinnewijn 2015; Kőszegi 2014).

For example, Hoffman and Burks (2020) find that worker overconfidence may be important for optimal job design and compensation. As a result, overconfident workers might opt for the piece rate (i.e., pay-per-use) instead of the flat income, since they estimate that they will earn more under the piece rate. Similarly, our above results on satisfaction can also be extended to an employment context, since unsatisfied employees are more likely to quit, increasing firms' turnover cost. Thereby, for a long-term perspective, optimal job and compensation design should also take employee satisfaction into account.

\subsection{Limitations and future research}

We acknowledge some limitations of our research that provide avenues for future work. The first limitation relates to the external validity of our experiment, especially the sequence of tasks. In real markets, people are heterogeneous with regard to 
overconfidence, which may affect their tariff-choice decisions. Thus, overconfidence may drive tariff-choice decisions without a preceding addition or number sequence task. Nevertheless, other activities or decisions prior to a tariff-choice decision might also be able to trigger comparable effects on consumers' tariff-choice behavior. The important question is whether they induce overconfidence or underconfidence and whether, as a result, consumers will form biased beliefs regarding their expected consumption. It would be interesting to investigate whether real-life situations (e.g., exam/ job success or failure) shift overconfidence and influence tariff-choice decisions in predictable ways.

Another aspect related to the external validity of our study concerns the experimental implementation of the tariffs. Specifically, we paid participants a bonus that was reduced dependent on their chosen tariff and their behavior (pay-per-use option only) under their chosen tariff. However, in the case of gym and mobile phone contracts, for example, consumers usually have to pay a certain amount for each unit consumed, rather than having to make a large upfront payment, which is then reduced. Yet, there are also pay-per-use types in which an upfront fee needs to be paid-like in the case of a book of ten tickets used in gyms (e.g., as in DellaVigna and Malmendier 2006) or public transportation. Given that our design choice enabled us to make participants' behavior in the experiment consequential and that such pay-per-use types exist in the field, we opted for the described experimental implementation. However, future research should explore the impact of alternative ways of modeling the benefit of a contract.

Several studies have shown that biases may diminish over time through learning (e.g., Grubb and Osborne 2015; Miravete 2002). Because we analyze a single tariffchoice decision, we cannot observe the long-term effects of overconfidence on tariff choice. We leave the analysis of these effects to future research.

In addition, future research could explore whether the effects hold in particular contexts (e.g., car sharing) and whether context-specific differences exist. As we conducted our experiment in a rather controlled online environment, further research in the field would be interesting.

Finally, potential moderators of the effect of overconfidence on tariff choice seem worth exploring. Specifically, it is an open question whether and to what extent the effects of overconfidence on tariff choice are moderated through experience or specific contexts. In this regard, it might also be interesting to consider varying the stakes. All else being equal, higher stakes should induce people to invest more cognitive effort, which in turn should result in less biased decisions. Furthermore, time pressure could be a moderator in tariff-choice decisions because this decision impairment may attenuate or amplify the effect of overconfidence on tariff choice. Eventually, overconfidence is typically correlated with risk preferences. One possible way to examine risk preferences as a moderator of the effect of overconfidence on tariff choice is to experimentally manipulate whether decision makers choose a tariff for themselves or for someone else. Prior research found that when an individual makes a decision for an anonymous third party, there is a tendency to exhibit 
less risk aversion (Chakravarty et al. 2011). This reduction in risk aversion is relative to the participants' own preferences, and it is also relative to their beliefs about the preferences of others. Thus, manipulating whether people are choosing a tariff for themselves vs. for a third party should also influence their risk preferences and thus enable researchers to explore risk preferences as a moderator of the effect of overconfidence on tariff choice.

Acknowledgements The authors would like to thank Dorothea Kübler and participants of the 5th CRC TRR meeting in Berlin for their helpful and constructive comments. The authors gratefully acknowledge financial support by the Deutsche Forschungsgemeinschaft through CRC TRR 190 (Project Number 280092119).

Funding Open Access funding enabled and organized by Projekt DEAL.

Open Access This article is licensed under a Creative Commons Attribution 4.0 International License, which permits use, sharing, adaptation, distribution and reproduction in any medium or format, as long as you give appropriate credit to the original author(s) and the source, provide a link to the Creative Commons licence, and indicate if changes were made. The images or other third party material in this article are included in the article's Creative Commons licence, unless indicated otherwise in a credit line to the material. If material is not included in the article's Creative Commons licence and your intended use is not permitted by statutory regulation or exceeds the permitted use, you will need to obtain permission directly from the copyright holder. To view a copy of this licence, visit http://creativecommons.org/licenses/by/4.0/.

\section{Appendix}

Table 3 depicts the manipulation of overconfidence, Fig. 5 shows the usage task, Fig. 6 depicts the tariff-choice options, and Table 4 contains the scales and items used in the experiment.In a memory game you need to match pairs of tiles.

Table 3 Manipulation of overconfidence

\begin{tabular}{lll}
\hline Treatment & Underconfidence & Overconfidence \\
\hline Instructions & $\begin{array}{c}\text { Please provide the number or letter } \\
\text { that logically follows next } \\
\text { in the series of numbers or letters }\end{array}$ & $\begin{array}{c}\text { Please provide the answer } \\
\text { to the additions }\end{array}$ \\
Question 1 & $8,2,6,4,7,3,5, ?$ & $29+55=$ \\
Question 2 & $7,7,15,21,37,57, ?$ & $71+15=$ \\
Question 3 & $1,2,3,5,7,11,15, ?$ & $31+63=$ \\
Question 4 & $1,3,5,11,21,43, ?$ & $13+51=$ \\
Question 5 & a, d, h, m, ? & $47+44=$ \\
Question 6 & $2,4,6,10,16, ?$ & $60+39=$ \\
Question 7 & & $11+40=$ \\
Question 8 & & $43+14=$ \\
Question 9 & & $35+40=$ \\
Question 10 & & $32+23=$ \\
Question 11 & & $40+7=$ \\
Question 12 & & $50+11=$ \\
\hline
\end{tabular}


You turn over one tile and then try to find a matching tile. You are going to solve the memory game below (in a different order), for which you can receive a bonus payment

\section{Example:}
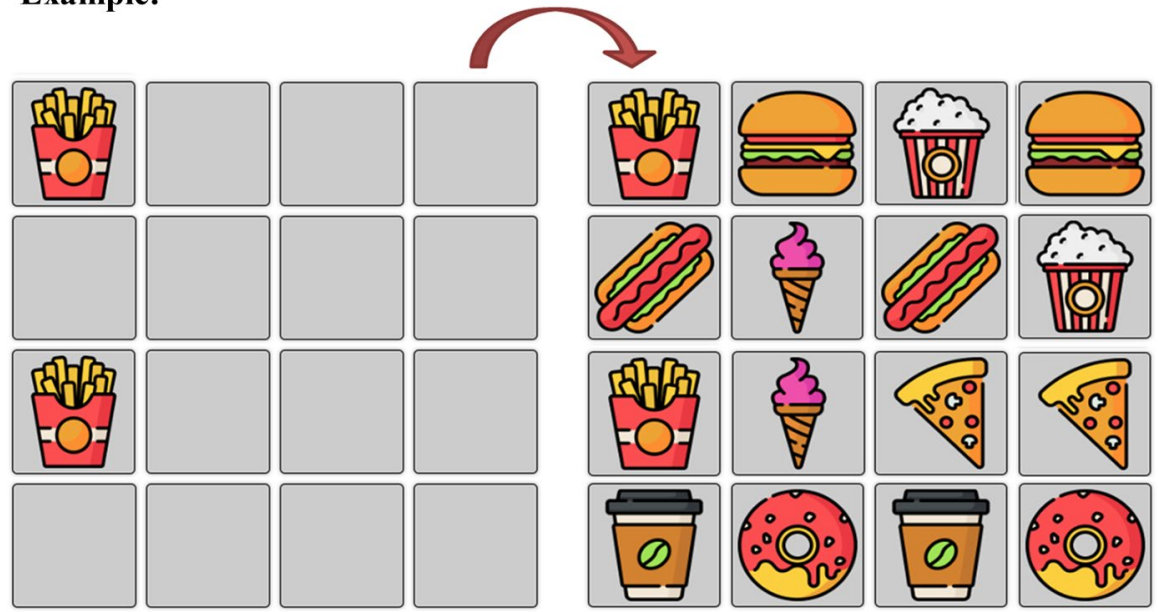

Fig. 5 Usage task
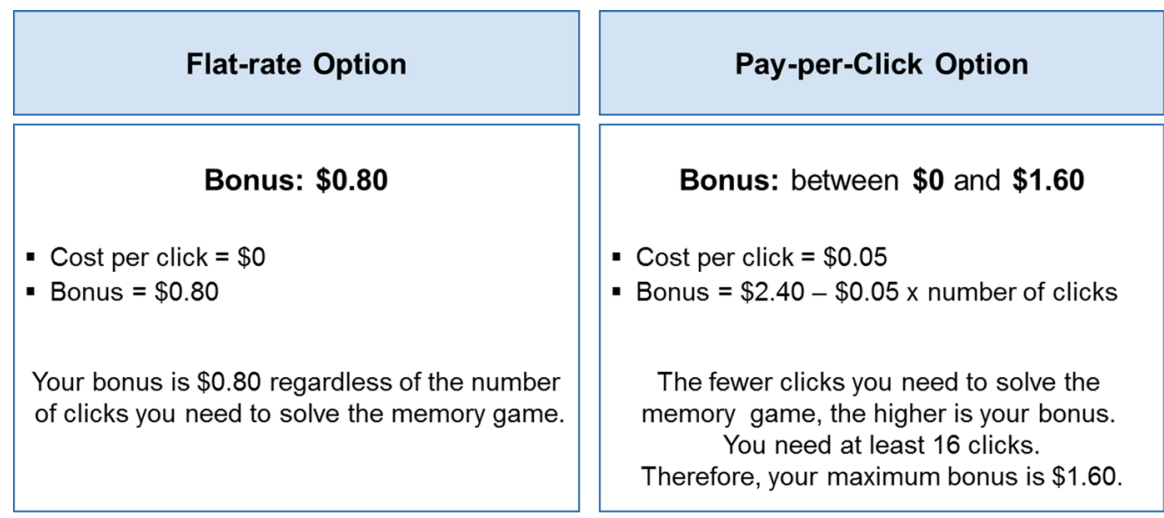

Bonus: between $\$ 0$ and $\$ 1.60$

- Cost per click $=\$ 0.05$

- Bonus $=\$ 2.40-\$ 0.05 \times$ number of clicks

The fewer clicks you need to solve the memory game, the higher is your bonus. You need at least 16 clicks.

Therefore, your maximum bonus is $\$ 1.60$.

Fig. 6 Tariff-choice options 


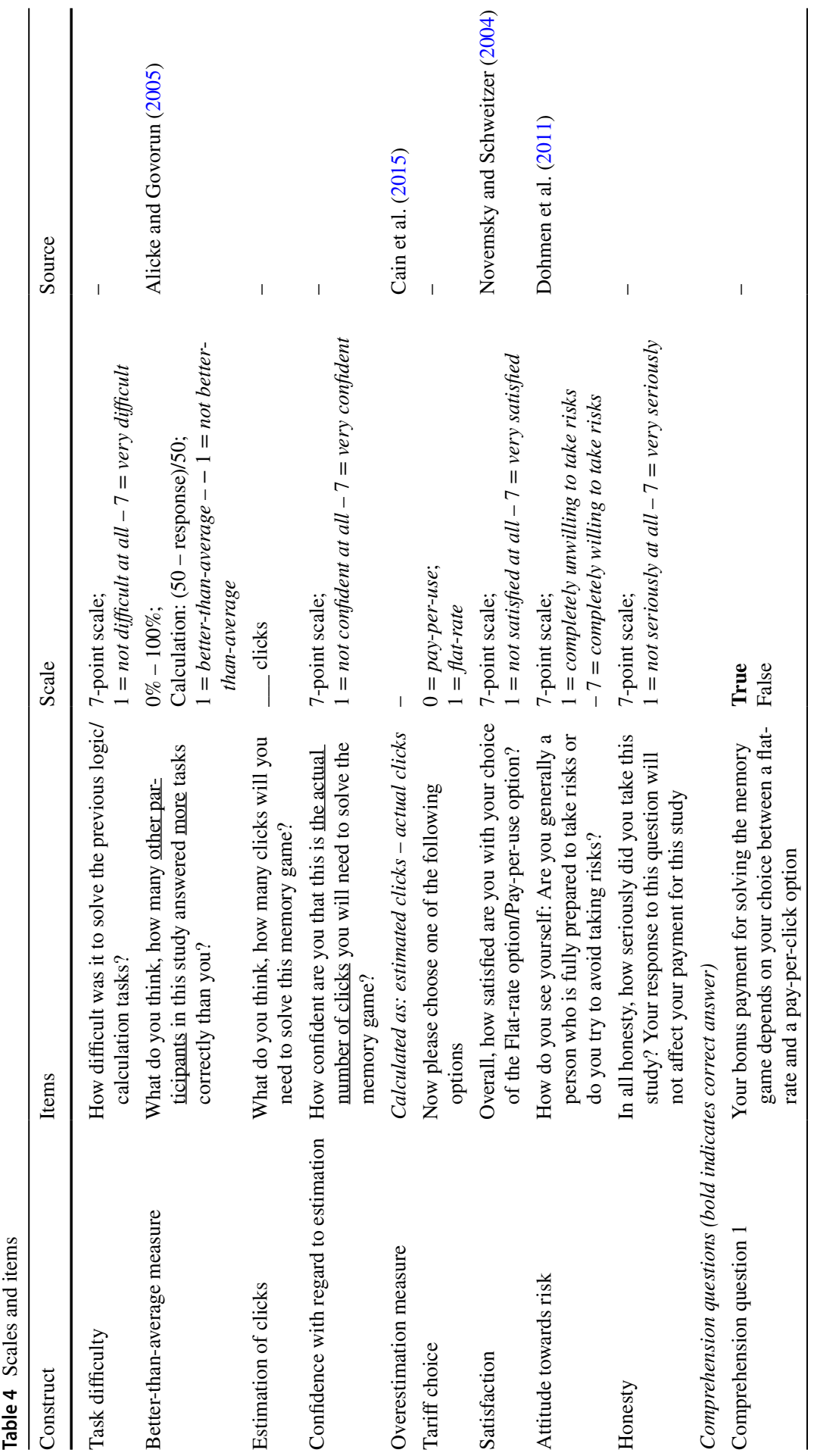




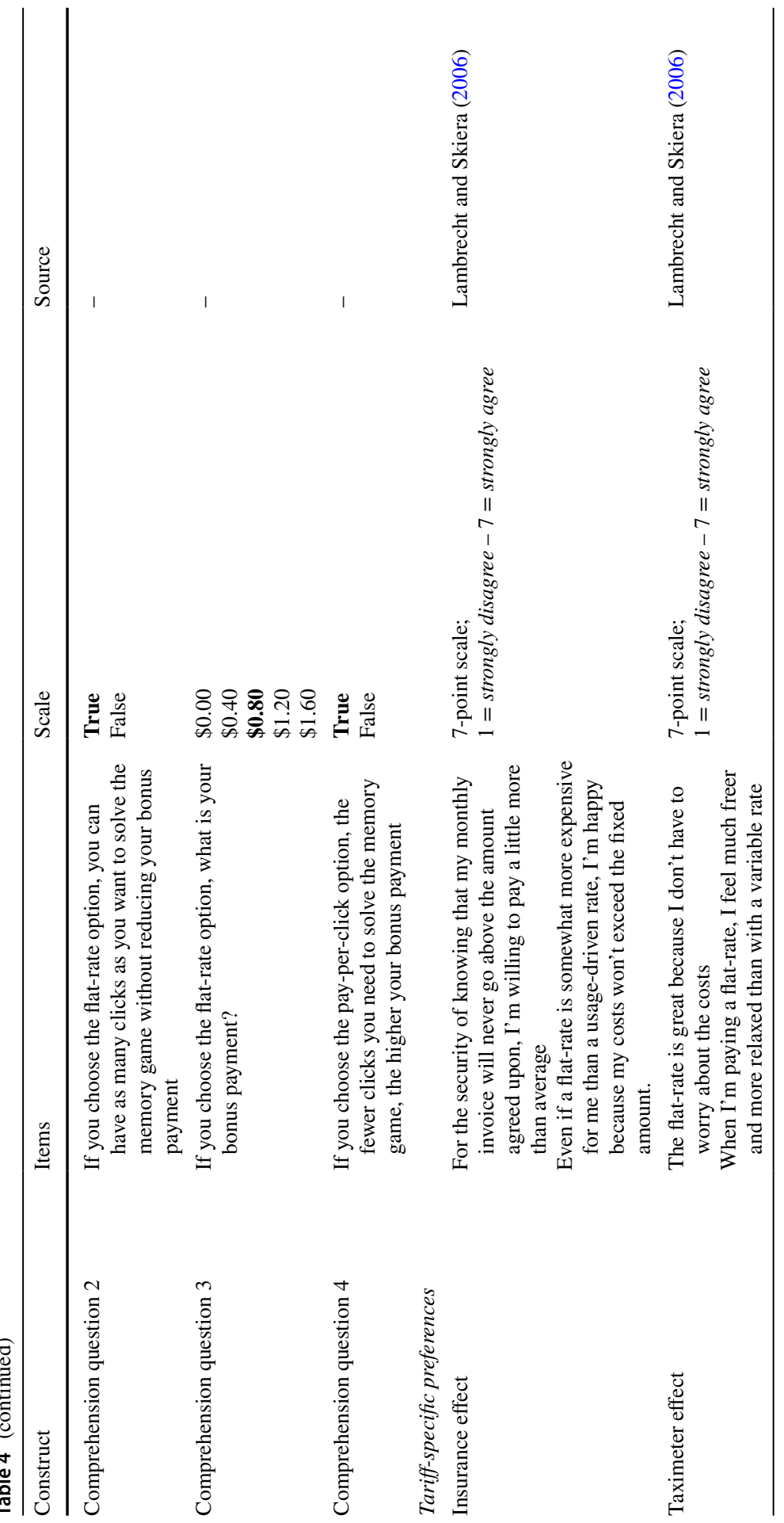




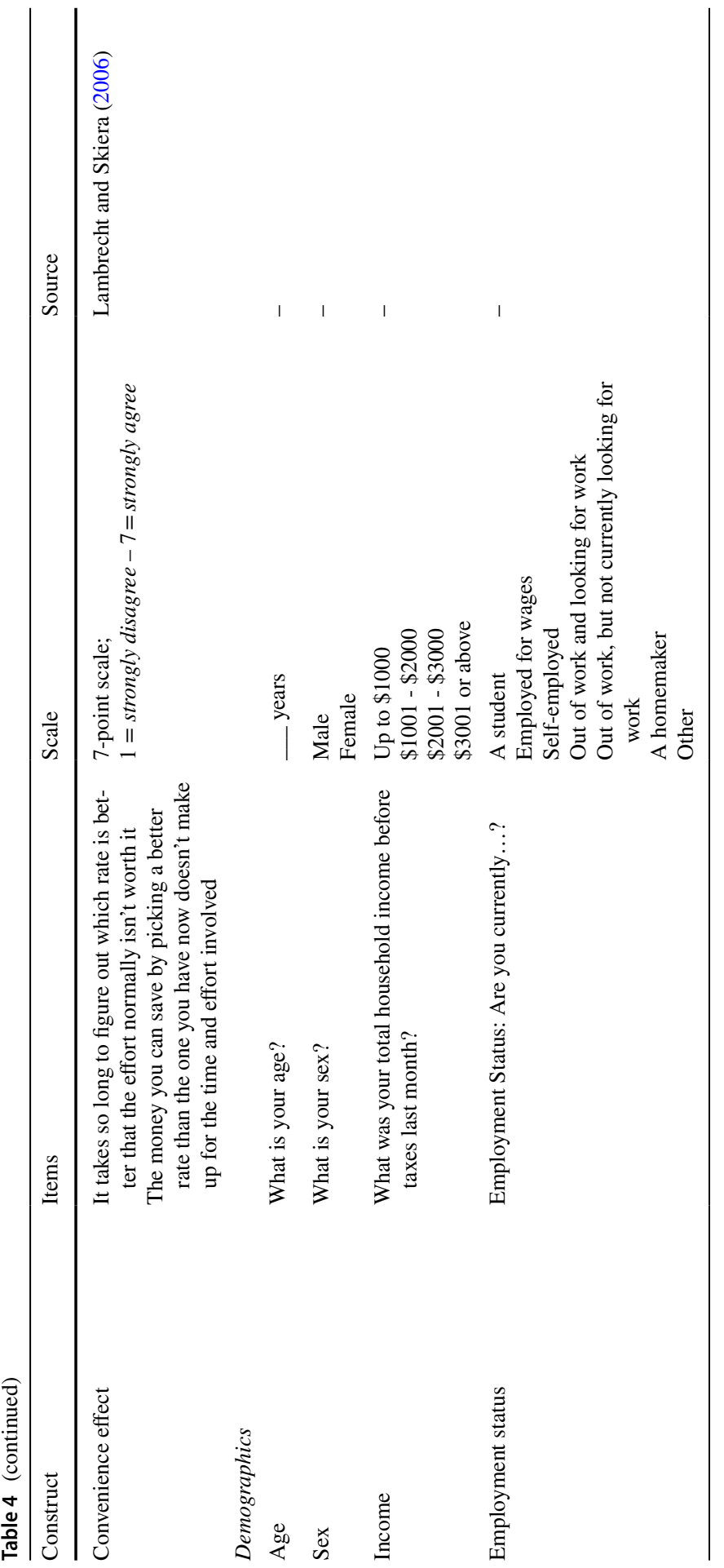




\section{References}

Alicke MD, Govorun O (2005) The better-than-average effect. In: Alicke MD, Dunning DA, Krueger JI (eds) Studies in self and identity. The Self in Social Judgment, pp 85-106

Becker JU, Spann M, Schulze T (2015) Implications of minimum contract durations on customer retention. Mark Lett 26(4):579-592

Cain DM, Moore DA, Haran U (2015) Making sense of overconfidence in market entry. Strateg Manag J 36(1):1-18

Camerer C, Lovallo D (1999) Overconfidence and excess entry: an experimental approach. Am Econ Rev 89(1):306-318

Chakravarty S, Harrison GW, Haruvy EE, Rutström EE (2011) Are you risk averse over other people's money? South Econ J 77(4):901-913

Dargnies M-P, Hakimov R, Kübler D (2019) Self-confidence and unraveling in matching markets. Manag Sci 65(12):5449-5956

DellaVigna S (2009) Psychology and economics: evidence from the field. J Econ Lit 47(2):315-372

DellaVigna S, Malmendier U (2006) Paying not to go to the gym. Am Econ Rev 96(3):694-719

Ding M, Grewal R, Liechty J (2005) Incentive-aligned conjoint analysis. J Mark Res 42(1):67-82

Dohmen T, Falk A, Huffman D, Sunde U, Schupp J, Wagner GG (2011) Individual risk attitudes: measurement, determinants, and behavioral consequences. J Eur Econ Assoc 9(3):522-550

Dowling K, Guhl D, Klapper D, Spann M, Stich L, Yegoryan N (2020) Behavioral biases in marketing. J Acad Mark Sci 48(3):449-477

Gächter S, Huang L, Sefton M (2016) Combining "real effort" with induced effort costs: the ball-catching task. Exp Econ 19(4):687-712

Glaser M, Weber M (2007) Overconfidence and trading volume. Geneva Risk Insur Rev 32(1):1-36

Grubb MD (2009) Selling to overconfident consumers. Am Econ Rev 99(5):1770-1807

Grubb MD (2015a) Consumer inattention and bill-shock regulation. Rev Econ Stud 82(1):219-257

Grubb MD (2015b) Overconfident consumers in the marketplace. J Econ Perspect 29(4):9-35

Grubb MD, Osborne M (2015) Cellular service demand: biased beliefs, learning, and bill shock. Am Econ Rev 105(1):234-271

Hayes AF (2013) Introduction to mediation, moderation, and conditional process analysis: a regression based approach. The Guilford Press, New York

Hempel J (2018) Why lyft is trying to become the next subscription business. https:/www.wired.com/ story/why-lyft-is-trying-to-become-the-next-subscription-business/. Accessed 30 Nov 2020

Herweg F, Mierendorff K (2013) Uncertain demand, consumer loss aversion, and flat-rate tariffs. J Eur Econ Assoc 11(2):399-432

Hoffman M, Burks SV (2020) Worker overconfidence: field evidence and implications for employee turnover and firm profits. Quant Econ 11(1):315-348

Horton JJ (2010) The dot-guessing game: a "fruit fly" for human computation research. SSRN Electron J. https://doi.org/10.2139/ssrn.1600372

Iyengar R, Jedidi K, Essegaier S, Danaher PJ (2011) The impact of tariff structure on customer retention, usage, and profitability of access services. Mark Sci 30(5):820-836

Kőszegi B (2014) Behavioral contract theory. J Econ Lit 52(4):1075-1118

Lambrecht A, Skiera B (2006) Paying too much and being happy about it: existence, causes, and consequences of tariff-choice biases. J Mark Res 43(2):212-223

Leider S, Şahin Ö (2014) Contracts, biases, and consumption of access services. Manag Sci 60(9):2198-2222

Lichtenstein S, Fischhoff B, Phillips LD (1982) Calibration of probabilities: the state of the art to 1980. In: Slovic P, Tversky A, Kahneman D (eds) Judgment under uncertainty. Heuristics and biases. Cambridge University Press, Cambridge, pp 306-334

Loewenstein G, O’Donoghue T, Rabin M (2003) Projection bias in predicting future utility. Q J Econ 118(4):1209-1248

Malmendier U, Tate G (2015) Behavioral CEOs: the role of managerial overconfidence. J Econ Perspect 29(4):37-60

Mang S, Post D, Spann M (2012) Pricing of flexible products. RMS 6(4):361-374

Matousek M (2018) Uber just launched a subscription service for $\$ 14.99$ a month that allows users to avoid surge pricing. https://www.businessinsider.de/uber-launches-ride-pass-subscription-service2018-10?r=US\&IR=T. Accessed 30 Nov 2020 
Miravete EJ (2002) Choosing the wrong calling plan? Ignorance and learning. Am Econ Rev 93(1):297-310

Moore DA, Healy PJ (2008) The trouble with overconfidence. Psychol Rev 115(2):502-517

Niederle M, Vesterlund L (2007) Do women shy away from competition? Do men compete too much? Q J Econ 122(3):1067-1101

Novemsky N, Schweitzer ME (2004) What makes negotiators happy? The differential effects of internal and external social comparisons on negotiator satisfaction. Organ Behav Hum Decis Process 95(2):186-197

Nunes JC (2000) A cognitive model of people's usage estimations. J Mark Res 37(4):397-409

Rabin M (2002) A perspective on psychology and economics. Eur Econ Rev 46(4-5):657-685

Reiss PC (2011) Structural workshop paper-descriptive, structural, and experimental empirical methods in marketing research. Mark Sci 30(6):950-964

Ren Y, Croson R (2013) Overconfidence in newsvendor orders: an experimental study. Manag Sci 59(11):2502-2517

Spinnewijn J (2015) Unemployed but optimistic: optimal insurance design with biased beliefs. J Eur Econ Assoc 13(1):130-167

Train KE, McFadden DL, Ben-Akiva M (1987) The demand for local telephone service: a fully discrete model of residential calling patterns and service choices. Rand J Econ 18(1):109-123

Uhrich F, Schumann JH, von Wangenheim F (2013) The impact of consumption goals on flat-rate choice. J Serv Res 16(2):216-230

Publisher's Note Springer Nature remains neutral with regard to jurisdictional claims in published maps and institutional affiliations. 